University of Nebraska - Lincoln

DigitalCommons@University of Nebraska - Lincoln

Faculty Publications, Department of Psychology

Psychology, Department of

January 2002

\title{
Prosocial Development in Early Adulthood: A Longitudinal Study
}

\author{
Nancy Eisenberg \\ Arizona State University \\ Ivanna K. Guthrie \\ Arizona State University \\ Amanda Cumberland \\ Arizona State University \\ Bridget C. Murphy \\ Arizona State University \\ Stephanie A. Shepard \\ Arizona State University
}

See next page for additional authors

Follow this and additional works at: https://digitalcommons.unl.edu/psychfacpub

Part of the Psychiatry and Psychology Commons

Eisenberg, Nancy; Guthrie, Ivanna K.; Cumberland, Amanda; Murphy, Bridget C.; Shepard, Stephanie A.; Zhou, Qing; and Carlo, Gustavo, "Prosocial Development in Early Adulthood: A Longitudinal Study" (2002). Faculty Publications, Department of Psychology. 298.

https://digitalcommons.unl.edu/psychfacpub/298

This Article is brought to you for free and open access by the Psychology, Department of at DigitalCommons@University of Nebraska - Lincoln. It has been accepted for inclusion in Faculty Publications, Department of Psychology by an authorized administrator of DigitalCommons@University of Nebraska - Lincoln. 


\section{Authors}

Nancy Eisenberg, Ivanna K. Guthrie, Amanda Cumberland, Bridget C. Murphy, Stephanie A. Shepard, Qing Zhou, and Gustavo Carlo 
Published in Journal of Personality and Social Psychology, 82:6 (2002), pp. 993-1006; doi: 10.1037/0022-3514.82.6.993

Copyright (C) 2002 American Psychological Association. Used by permission. "This article may not exactly replicate the final version published in the APA journal. It is not the copy of record.” http://www.apa.org/journals/

Submitted July 9, 2001; revised December 3, 2001; accepted December 11, 2001.

\title{
Prosocial Development in Early Adulthood: A Longitudinal Study
}

\author{
Nancy Eisenberg, Ivanna K. Guthrie, Amanda Cumberland, Bridget C. Murphy, \\ Stephanie A. Shepard, Qing Zhou, and Gustavo Carlo \\ Department of Psychology, Arizona State University
}

\begin{abstract}
Consistency of measures of a prosocial personality and prosocial moral judgment over time, and the interrelations among them, were examined. Participants' and friends' reports of prosocial characteristics were obtained at ages 2122, 23-24, and 25-26 years. In addition, participants' prosocial judgment was assessed with interviews and with an objective measure of prosocial moral reasoning at several ages. Reports of prosocial behavior and empathy-related responding in childhood and observations of prosocial behavior in preschool also were obtained. There was interindividual consistency in prosocial dispositions, and prosocial dispositions in adulthood related to empathy/sympathy and prosocial behavior at much younger ages. Interview and objective measures of moral reasoning were substantially interrelated in late adolescence/early adulthood and correlated with participants' and friends' reports of a prosocial disposition.
\end{abstract}

For many years, psychologists have debated whether there is an altruistic or prosocial personality that is enduring over time and situations (Gergen, Gergen, \& Meter, 1972). Piliavin, Dovidio, Gaertner, and Clark (1981) asserted that the search for an altruistic personality is futile, and Batson (1991) expressed doubts about its existence. Others (e.g., Penner \& Finkelstein, 1998; Staub, 1974) have argued that people do differ in the degree to which they consistently behave in caring ways.

Penner and Finkelstein (1998) defined the prosocial personality as "an enduring tendency to think about the welfare and rights of other people, to feel concern and empathy for them, and to act in a way that benefits them" (p. 526). Defined in this manner, the prosocial personality may include other-oriented values, cognitions, and prosocial actions as well as sympathy and empathy. Because it usually is impossible to unequivocally differentiate between other-oriented behaviors and those driven by less lofty motives, investigators have been concerned with internal processes, such as sympathy or empathy and moral cognitions (e.g., moral reasoning), believed to motivate other-oriented behavior.

Bridget C. Murphy is now at the Department of Psychology, University of Oklahoma. Stephanie A. Shepard is now at the Department of Counseling Psychology, University of Oregon. Gustavo Carlo is now at the Department of Psychology, University of Nebraska-Lincoln.

This research was supported by National Institute of Mental Health Grants 1 R01 HH55052 and 1 R01 MH60838 and by National Institute of Mental Health Research Scientist Development Award K02 MH00903 and Research Scientist Award K05 M801321 to Nancy Eisenberg. We thank the participants in our longitudinal samples and their friends who provided data. Gratitude also is due to the Tempe schools for their earlier participation in this research.

Corresponding author: Nancy Eisenberg, Department of Psychology, Arizona State University, Tempe, Arizona 85287
Empathy frequently has been defined as an emotional reaction elicited by and congruent with another's emotional state or condition (Eisenberg \& Fabes, 1998; Hoffman, 1982). Eisenberg et al. (1994) and Hoffman (2000) have argued that empathic responding often results in sympathy (concern for another based on the apprehension or comprehension of the other's emotional state or condition), although it also can lead to empathic overarousal (or personal distress, an aversive, self-focused emotional reaction to the apprehension or comprehension of another's emotional state or condition; Batson, 1991). Batson (1991) hypothesized that sympathy (called empathy by Batson) involves other-oriented motivation, whereas personal distress involves the egoistic motive of alleviating one's own aversive negative emotional state. Consistent with such theorizing, sympathy generally has been positively related to prosocial behavior, especially behavior that is likely to be based on other-oriented emotions and values (Batson, 1991; Eisenberg \& Fabes, 1998; Penner, in press). Moreover, cognitive perspective taking, which involves cognitively taking the role of the other or accessing information from memory to assist in one's understanding of another's situation, has been hypothesized to promote sympathy (Batson, 1991; Hoffman, 1982) and has been empirically linked to prosocial behavior (e.g., Eisenberg, Zhou, \& Koller, 2001; Underwood \& Moore, 1982). Thus, sympathy, perspective taking, and, to a limited degree, empathy can be considered measures of a prosocial disposition that are expected to motivate altruistic behavior (Hoffman, 2000; Penner, Fritzsche, Craiger, \& Freifeld, 1995).

Because individuals' reasoning regarding moral decisions (i.e., moral reasoning) is believed to influence the quality of their moral behavior (Eisenberg, 1986; Hoffman, 1987; Kohlberg, 1981), rea- 
soning about prosocial moral issues can be viewed as an important component of prosocial functioning. Until the 1970s, however, nearly all of the research on moral judgment was based on Kohlberg's (1981) pioneering theory and interview methods, which focus primarily on principles of justice (e.g., moral conflicts in which rules, laws, authorities' dictates, and formal obligations are central). Although there has been much less research on positive aspects of moral reasoning (Eisenberg, 1986; Garmon, Basinger, Gress, \& Gibbs, 1996; Gilligan \& Attanucci, 1988), there is a growing body of work on care-related concerns in moral conflicts and on prosocial moral reasoning-reasoning about moral dilemmas in which one person's needs or desires conflict with those of others in a context in which the role of prohibitions, authorities' dictates, and formal obligations is minimal (Eisenberg, Carlo, Murphy, \& Van Court, 1995; Eisenberg-Berg, 1979). Although moral reasoning generally is not viewed as an aspect of personality, it seems to contribute to the consolidation of a prosocial disposition and could be expected to correlate with prosocial personal characteristics.

The purpose of the present study was to obtain evidence for the existence of a prosocial personality in adulthood, with its roots in childhood. To this end, we examined the consistency of various measures of prosocial functioning across reporters and time and the stability of aspects of individuals' prosocial functioning over time (i.e., in terms of interindividual ranking in correlations).

\section{Evidence for the Existence of a Prosocial Personality}

Data from a longitudinal study were used to examine these issues. On the basis of both theory and prior research (e.g., Eisenberg, 1986; Hoffman, 2000; Penner \& Finkelstein, 1998; Staub, 1974), we expected to find modest to moderate consistency both among components of a prosocial personality and between these components and adults' moral judgments about prosocial moral dilemmas. In addition, consistency in prosocial functioning was expected over years, although less consistency was predicted for moral reasoning than for prosocial personality characteristics because level of moral judgment is believed to reflect change in structure of the reasoning (i.e., how it is cognitively organized, the level of perspective taking underlying it), as well as in its content, from childhood into adulthood (Colby \& Kohlberg, 1987; Colby, Kohlberg, Gibbs, \& Lieberman, 1983; Eisenberg, 1986; Kohlberg, 1981).

Two types of data are pertinent to the issue of whether there are stable and enduring individual differences in the tendency to care about and help others: (a) data on the consistency of prosocial behaviors and dispositions across contexts, measures, or reporters, and (b) data on the stability of prosocial tendencies over time. Evidence of consistency in prosocial responding across concurrent measures, contexts, and reporters is mixed. Findings of cross-situational consistency are modest for children, adolescents, and adults (Eisenberg \& Fabes, 1998; Graziano \& Eisenberg, 1997), which is not surprising given that prosocial actions in different contexts often may reflect different motives. On the basis of the limited crosssituational consistency in helping behavior, Penner, Escarraz, and Ellis (1983) suggested that the search for the prosocial personality would be more fruitful if one looked for a constellation of traits that was associated with broad prosocial tendencies. However, research on the prosocial personality is limited, especially work that includes multiple reporters and methods.
Surprisingly few investigators have studied the relations of young adults' prosocial and empathy-related dispositions to their prosocial moral judgment. There are numerous reasons to expect an association. First, researchers such as Kohlberg and Candee (1984) and Rest (1979) have argued that moral reasoning influences individuals' moral decisions and social behavior. Moreover, Hoffman (1987, 2000) suggested that empathy/sympathy bonds with moral principles, provides the motivational force to act on those principles, and stimulates the development of internalized moral reasoning reflecting concern for others' welfare. In addition, Eisenberg (1986) suggested that sympathy primes the use of preexisting other-oriented moral cognitions.

Consistent with theory, moral reasoning, including prosocial moral judgment, generally has been modestly correlated with prosocial behaviors such as helping or sharing, especially costly prosocial behaviors (Eisenberg, 1986; Janssens \& Dekovic, 1997). Specifically, children's and adolescents' prosocial behavior generally has been positively correlated with needs-oriented (primitive empathic) reasoning and negatively related to hedonistic reasoning; in addition, it sometimes has been positively correlated with a composite measure of prosocial moral reasoning, especially at ages 1516 to 19-20 (Eisenberg et al., 1995; Eisenberg, Miller, Shell, McNalley, \& Shea, 1991). The relation of prosocial moral reasoning to prosocial behavior and empathy or sympathy seldom has been examined in adulthood. It has been argued that the relation between moral reasoning and behavior becomes even stronger in adulthood than in childhood because higher level reasoning is associated with the "progressive stripping away of bases for justifying behavior that are extrinsic to principle" (Rholes \& Bailey, 1983, p. 104); this results in stronger motivation to maintain consistency between attitudes and behaviors at higher stages of development (Kohlberg \& Candee, 1984). Thus, in the present study, self-and friend-reported prosocial tendencies (e.g., helping, sympathy, perspective taking) in early adulthood were expected to be positively related to concurrent overall reasoning level and negatively correlated with hedonistic reasoning.

There also is empirical support that level and/or type of prosocial moral reasoning is related to dispositional perspective taking or sympathy in childhood and adolescence (Carlo, Eisenberg, \& Knight, 1992; Eisenberg et al., 1987, 1991, 1995; Underwood \& Moore, 1982). Generally, sympathy and perspective taking have been associated with more other-oriented, less self-oriented, and/ or higher level prosocial moral reasoning. To our knowledge, these relations have not been examined in adults older than 19 or 20 . In the present study, we examined the association of measures of sympathy, perspective taking, and prosocial behavior to prosocial moral reasoning, as assessed with both interviews and an objective measure of prosocial moral judgment. As has been found in adolescence, higher level moral reasoning was expected to correlate with greater sympathy and perspective taking.

When one examines relations between measures of a prosocial personality or moral judgment and specific prosocial behaviors, it is important to consider the motivational significance of the particular prosocial behavior when possible. Eisenberg-Berg and Hand (1979) hypothesized that preschoolers' spontaneous sharing behaviors, which often involve a cost to the child, are more other-oriented than are everyday helping behaviors, which generally entail little cost or are performed merely to comply with peers' requests. They found that spontaneous sharing, but not spontaneous help- 
ing or compliant sharing or helping, was associated with higher level needs-oriented prosocial moral reasoning (Eisenberg-Berg \& Hand, 1979). Moreover, spontaneous prosocial behavior but not compliant prosocial behavior has been correlated with sympathy in young children (Eisenberg, McCreath, \& Ahn, 1988; also see Larrieu \& Mussen, 1986). In contrast, frequency of compliant prosocial behavior has been associated with preschoolers' personal distress when exposed to another's negative emotion and seems to be linked to low to average social competence (Eisenberg, Cameron, Tryon, \& Dodez, 1981; Eisenberg et al., 1988). Furthermore, costly but not low-cost prosocial behaviors have been associated with higher level moral judgment in childhood and adolescence (Eisenberg et al., 1987; Eisenberg \& Shell, 1986). Eisenberg and Shell (1986) hypothesized that low-cost behaviors are performed rather automatically, without much cognitive reflection, moral or otherwise. Thus, one would expect measures of a prosocial personality in adulthood to relate to earlier prosocial measures primarily if the latter reflected an other-orientation (e.g., sympathy/empathy) or costly, spontaneous prosocial action. Prosocial measures in adulthood were not expected to relate to compliant prosocial behavior or low-cost prosocial behavior (e.g., helping) in childhood.

Research examining consistency of prosocial tendencies across substantial periods of time is rarer than is work on concurrent consistency among aspects of prosocial tendencies. Several researchers have reported modest correlations over a year or a few years in childhood for raters' perceptions of children's prosocial behavior (e.g., Bar-Tal \& Raviv, 1979; Block \& Block, 1973) or for actual donating or helping behavior (Eisenberg et al., 1987); in the 2nd decade of life, self-reports or other reports of prosocial behavior or sympathy have been correlated over 2 to 8 years (Davis \& Franzoi, 1991; Eisenberg et al., 1995). Of particular note, in the sample in this study, observed naturally occurring, spontaneous, costly prosocial behaviors (i.e., spontaneous sharing) in the preschool years, but not other compliant or less costly prosocial behaviors, generally were associated with sympathy and a prosocial disposition in adolescence and early adulthood and were marginally positively related to self-reported prosocial dispositions (but not friend-reported prosociality) at age 23-24 (although compliant sharing was positively related to self-reported helping in adolescence; Eisenberg et al., 1999). To our knowledge, there have been no longitudinal studies of the consistency of a prosocial orientation from adolescence into the 3 rd decade of life.

There are several reasons to expect consistency in prosocial responding across time. First, theorists have suggested that prosocial behavior and empathy-related responding have a genetic basis (e.g., Hoffman, 1981), and researchers have obtained evidence of their heritability (Emde et al., 1992; Loehlin \& Nichols, 1976; Rushton, Fulker, Neale, Nias, \& Eysenck, 1986; Zahn-Waxler, Robinson, \& Emde, 1992). Moreover, both prosocial behavior and sympathy are correlated with temperamental predispositions such as regulation (e.g., Eisenberg, Fabes, Karbon, et al., 1996; Eisenberg, Fabes, Murphy, et al., 1996; Rothbart, Ahadi, \& Hershey, 1994) that likely have a constitutional basis (albeit influenced by the environment; Rothbart \& Bates, 1998). Thus, biological factors could account not only for interspecies but also for intraspecies variation in prosocial responding.

Environmental factors, in addition to heredity, likely contribute to the development of a prosocial disposition. Bergeman et al. (1993) found that agreeableness (which includes prosocial tenden- cies; Graziano \& Eisenberg, 1997) was influenced by shared rearing environmental influences. Krueger, Hicks, and McGue (2001) also found that altruism was influenced primarily by shared and nonshared environmental influences. Moreover, numerous parental child-rearing practices as well as the security of attachment in infancy have been associated with the development of prosocial behavior and sympathy (Eisenberg \& Fabes, 1998; Kestenbaum, Farber, \& Sroufe, 1989). In fact, child-rearing practices of parents of 5-year-old children have predicted the children's empathy at age 31 (Koestner, Franz, \& Weinberger, 1990). Thus, one might expect some consistency in prosocial behavior during childhood and adolescence due to consistency in socialization experiences. Moreover, because moral judgment may change in qualitative ways with increases in the abilities to take others' and society's perspective and to think abstractly (Kohlberg, 1981), it is unclear to what extent one can expect moral judgment to be consistent across early adulthood and to relate to prosocial tendencies at a younger age.

In summary, consistency across measures of a prosocial disposition and between measures of such a disposition and prosocial moral reasoning was expected in early adulthood. In addition, individual measures (or composite measures) of prosocial responding or prosocial moral judgment were expected to be consistent over time, although more so for measures of traits such as sympathy, perspective taking, and reported prosocial behavior than for moral reasoning. Further, in general, prosocial behavior, sympathy, and perspective taking in childhood and adolescence were expected to relate to prosocial dispositions in adulthood; the exception was for childhood measures of prosocial behavior that tap compliant and/ or low-cost prosocial behavior, which were not expected to predict later prosocial dispositions. Finally, because moral judgment may change in qualitative ways with increases in the abilities to take others' and society's perspective and to think abstractly (Kohlberg, 1981), it was unclear to what extent one might expect moral judgment to relate to prosocial tendencies at a younger age.

\section{Method}

\section{Study Participants}

The participants in this study were recruited when they were preschoolers in a university-run preschool used primarily by families from the community (Eisenberg-Berg \& Hand, 1979). The longitudinal cohort consisted of 16 women and 16 men (all Euro-American, except 2 of Hispanic origin) who had been interviewed nine times previously, at ages $4-5,5.5-6.5,7-8,9-10,11-12,13-14,15-16,17-18$, and 19-20 years (at 204, 186, 168, 144, 120, 96, 72, 48, and 24 months prior to the first assessment in this study; see Eisenberg et al., 1987, 1991, 1995, 1999). Three additional 2-year follow-ups are discussed in this article (Assessments 10 to 12 ); the 12 testing sessions henceforth are referred to as Times 1 to 12 (T1 to T12). The mean age of the participants at T10 was 258 months (range $=247-267$ months, approximately age $21-22$ years); they were approximately $23-24$ years $(M=281.00$ months, $S D=4.50)$ and 25-26 years $(M=305.00$ months; $S D=4.02)$ at the T11 and T12 follow-ups, respectively. No participants were lost from T3 to T10 (although interviews could not be obtained for some participants at T9 and $\mathrm{T} 10$ ), 1 refused any participation at T11 (so $n=31$ at T11) but not at T12 $(n=32)$, and 5 additional children were lost when they were young ( 3 boys, 2 girls; the original sample was 37 children). Mean years of maternal and paternal education for this sample (as reported at T8) were 16.0 and 17.0, respectively (range $=12-20$ years for both). At age 23-24 (T11), 2 of the participants had junior college degrees, 14 had graduated 
college ( 4 of whom were in graduate school), 1 had some college but did not seem to be in school, 10 were still in college, and 4 were high school graduates with very little or no college education. At T12, 2 reported advanced degrees (a law degree or a master's) and 1 was in law school, 16 more had graduated from college ( 1 had some master's training), 8 were still earning a bachelor's degree, 2 had quit college or had a 2 -year degree, and 3 had only a high school education. Occupations of those who had not finished 4 years of college included retail sales, data entry, homemaking, a nail technician who owned her own business, and a flight attendant. Occupations for college graduates were diverse; the graduates included a music teacher, a lawyer, an associate investment banker, 2 sales representatives, 2 account managers, a police officer, a dispatcher for the police department, a chemist, a corporate communications expert, and an Internet services specialist. One person was unemployed.

\section{Instruments}

\section{Prosocial Behavior and Orientation}

A variety of measures were used to assess components of a prosocial personality at various ages. At T10 to T12, all measures were selfor friend reported; some earlier measures were behavioral or mother reported. Generally, the measures reflect the notion that a prosocial personality involves both helpfulness and other-oriented sympathy/empathy (Penner \& Finkelstein, 1998).

Self-reports. At T6, T7, and T8, children filled out a 23-item adapted version of Rushton, Chrisjohn, and Fekken's (1981) self-report helping scale, the Self-Report Altruism Scale. Children indicated on a 5-point scale (ranging from never to very often) how frequently they engaged in 23 behaviors, such as giving money to charity or volunteer work (alphas at $\mathrm{T} 10$ to $\mathrm{T} 12=.86, .90$, and .87 , respectively; Eisenberg et al., 1991, 1995). At T10 to T12, participants filled out a 14-item adapted version of Rushton et al.'s (1981) Self-Report Altruism Scale taken from Penner et al. $(1995 ; \alpha \mathrm{s}=.85, .67$, and .78 at $\mathrm{T} 10$ to T12, respectively) using the same response scale. This measure overlaps in items with the longer 23item version of the measure completed at T6 to T8 (but not T9).

At T10 to T12, as at T9, self-reported moral behavior also was assessed with portions of Weinberger's Adjustment Inventory (WAI; Weinberger, 1991, 1997). Items from the longer version of two restraint subscales that concerned moral behavior were used (rated $1=$ false; $5=$ true): Consideration of Others (e.g., "I often go out of my way to do things for other people"; 7 items; $\alpha$ s $=.78, .84$, and .83 at T10 to T12, respectively), and Suppression of Aggression (e.g., "I lose my temper and 'let people have it' when I'm angry"; 7 items; $\alpha$ s $=.76, .84$, and .85 at $\mathrm{T} 10$ to T12, respectively). Items within each subscale were averaged (see Eisenberg et al., 1995, for T9 alphas).

At T10 to T12, several measures of prosocial orientation were taken from Penner and Finkelstein's (1998) instrument; these included empathy-related responding (described below), social responsibility, and a care orientation. Specifically, a subset of 15 items from Schwartz's (1968) Ascription of Responsibility to the Self Scale (henceforth called social responsibility) was included (e.g., "If a good friend of mine wanted to injure an enemy of his/hers, it would be my duty to try to stop him/her"; 1 $=$ strongly disagree, $5=$ strongly agree $; \alpha$ at $\mathrm{T} 10, \mathrm{~T} 11$, and $\mathrm{T} 12=.81$, .70 , and .65 , respectively). Moreover, 4 items reflecting a care orientation (e.g., "My decisions are usually based on my concern for other people"; $\alpha$ s at $\mathrm{T} 10$ to $\mathrm{T} 12=.81, .81$, and .87 , respectively) were rated on the same scale.

Mothers' reports. Mothers rated children's prosocial behavior using a slightly adapted 23-item version of the Rushton et al. (1981) scale at T6, T7, and T8 and the same response scale. The scale was very similar to the one filled out by the child participants. Alphas could not be computed because mothers frequently used the additional option of don't know (Eisenberg et al., 1991, 1995).
Friends' reports. At T10, T11, and T12, participants were asked to provide the names of up to 3 friends who might be willing to fill out short questionnaires about the participants. At T10, reports from at least 1 friend were obtained for 28 participants, and reports for 2 and 3 friends were obtained for 20 and 11 participants, respectively (for a total of 59 friends). Analogous numbers were 24,18 , and $6($ total $=48)$ at $\mathrm{T} 11$ and $23,21$, and 10 (total $=54)$ at T12. Only 9 friends were the same individuals at T10 and T11, and 17 of the same individuals were friends at T11 and T12. Mean lengths of the friendships at T10 to T12, as reported by friends, were 68, 86, and 101 months, respectively. If reports from more than 1 friend were obtained, they were averaged across each item on each questionnaire to produce more reliable measures (Epstein, 1979).

Friends responded to items from the short form of the WAI rating items, which contains 3 items per scale. Items on these subscales were similar to those used in the participant-report measures pertaining to consideration of others and suppression of aggression. Alpha coefficients at $\mathrm{T} 10$ to $\mathrm{T} 12$ for the 3 -item scales were $.88, .88$, and .83 , respectively, for Consideration of Others and $.85, .69$, and .61, respectively, for Suppression of Aggression. Friends also reported on participants' social responsibility using 10 of the same items filled out by participants (with slight changes in wording; $\alpha$ s at T10 to T12 were .72, .85, and .68, respectively).

Observed prosocial behavior in preschool. At T1, children were observed by at least two coders in the preschool in random order for a minimum of seventy 2-min timings (and a maximum of 113) over 6 to 11 weeks. Six observers coded each instance of three prosocial behaviors: (a) sharing - the child gives away or allows another child temporary use of a material object previously in the child's possession (but not as part of a game; e.g., sharing of tea cups when playing tea was not coded as sharing); (b) helping - the child attempts to alleviate another's nonemotional needs; for example, assists another by giving information, helps another with a task, or offers an object not previously in the giver's possession (these behaviors were not coded as helping if they occurred as part of cooperative play and involved the completion of a mutual goal); and (b) offers comfort - the child attempts to alleviate the emotional needs of another; for example, tries to make another feel better when in distress. Each behavior was coded as having occurred spontaneously, as having occurred in response to a verbal or nonverbal request from a peer (e.g., "asked for" or compliant prosocial behavior), or that it could not be determined whether the prosocial action was spontaneous. Comforting was very infrequent and was combined with helping (see Eisenberg-Berg \& Hand, 1979). The final categories of prosocial behavior were proportions of time per 2-min observance of spontaneous sharing, compliant sharing, spontaneous helping, and compliant helping. As reported in Eisenberg et al. (1999), mean interrater reliabilities ranged from $75 \%$ to $86 \%$ exact agreement (computed only during 2-min intervals in which at least one observer viewed a prosocial behavior).

\section{Empathy-Related Responding}

Reports of empathy-related responding were obtained from participants and friends.

Self-reports. For our assessment of empathy-related responding at T10 to T12, participants completed two 7-item subscales of Davis's (1983, 1994) Interpersonal Reactivity Index (IRI): Sympathy or Empathic Concern (the tendency to experience feelings of warmth and concern for others; e.g., "I have tender, concerned feelings for people less fortunate than me"; $\alpha \mathrm{s}=.81, .83$, and .82 , respectively), and Perspective Taking (the tendency to adopt the point of view of others; e.g., "I sometimes try to understand my friends better by imagining how things look from their perspective"; $\alpha \mathrm{s}=.82, .80$, and .87 , respectively). These items also were part of Penner and Finkelstein's (1998) measure of a prosocial personality. Items were rated from $1=$ strongly disagree to $5=$ strongly agree. Items on each scale were averaged (after reversing items 
if appropriate). These same scales were completed at T7, T8, and T9 (but were rated on a 7-point scale at T9). Bryant's (1982) 22-item empathy scale (e.g., "It makes me sad to see a girl who can't find anyone to play with") was completed at $\mathrm{T} 4, \mathrm{~T} 5$, and $\mathrm{T} 6$.

Friends' reports. The friends' questionnaire packet included the seven Sympathy (Empathic Concern) items in the IRI plus one additional item (i.e., "My friend has a tendency to feel concern for others' misfortunes even when he/she doesn't know those people personally"; $\alpha$ s $=.89, .88$, and .94 for T10, T11, and T12, respectively) and six of the seven Perspective Taking items (modified slightly from the original Davis, 1983, items to create an other-report format; $\alpha$ s $=.84, .92$, and .87 for T10, T11, and T12, respectively). The item dropped from the Perspective Taking scale seemed particularly difficult for friends to answer (i.e., "My friend sometimes tries to understand his/her friends better by imagining how things look from their perspective"). At T9, friends responded to the same seven-item Sympathy and Perspective Taking scales as did participants (see Eisenberg et al., 1995).

Data Reduction of Measures of Prosocial and Empathy-Related Responding at T10 to T12

Self-report data. At T10 to T12, there were multiple measures of a prosocial orientation: sympathy, perspective taking, helping behavior, social responsibility, consideration for others, suppression of aggression, and care orientation. All correlations among these variables, except that between social responsibility and helping, were at least marginally significant at both T10 (correlations ranged from .34 to $.78, p \mathrm{~s}<.059$ or better) and T11 (correlations ranged from .30 to $.81, p \mathrm{~s}<.098$ or better).
At T12, all prosocial measures except self-reported helping were significantly interrelated (correlations ranged from .38 to .78). The T12 self-reported helping measure correlated at $p<.10$ with social responsibility, sympathy, and perspective taking; the correlations for the relations of this measure with other indices of prosociality were all .23 or higher. Moreover, at all three times, all these measures grouped on the same factor in a principle components factor analysis with a varimax rotation; loadings ranged from .57 to .88 at T10, from .53 to .88 at T11, and from .55 to .85 at T12. Although these factor analyses must be viewed with caution on the basis of the small sample size, they were consistent with the correlations. Thus, scores on these measures were standardized and averaged to form a composite prosocial index at each follow-up. We constructed a similar prosocial composite at T9 using scales pertaining to consideration of others, suppression of aggression, perspective taking, and sympathy (see Eisenberg et al., 1995). Because means of composite scores involving standardized items were zero, means for the individual scales are presented in Table 1.

Friends' reports. The friend measures at T10 (consideration of others, suppression of aggression, social responsibility, perspective taking, and sympathy) were all significantly interrelated, $r \mathrm{~s}(26)$ ranged from .39 to .72 , with the exception of the correlation between social responsibility and consideration for others. At T11, all friend measures were significantly correlated; $r \mathrm{~s}(22)=.52$ to .84 . At $\mathrm{T} 12$, all items were significantly related, $r \mathrm{~s}(21)=.47$ to .73 , with the exception that social responsibility and suppression of aggression were marginally related, $r(21)=.35, p<$ .097 , and sympathy and suppression of aggression were nonsignificantly correlated, $r(21)=.31$. Therefore, the various measures were standardized and averaged at each time period to form composite measures of

Table 1. Means and Standard Deviations of Major Variables at T10, T11, and T12

\begin{tabular}{|c|c|c|c|c|c|c|}
\hline \multirow[b]{2}{*}{ Measure } & \multicolumn{2}{|c|}{$\mathrm{T} 10$} & \multicolumn{2}{|c|}{$\mathrm{T} 11$} & \multicolumn{2}{|c|}{$\mathrm{T} 12$} \\
\hline & $M$ & $S D$ & $M$ & $S D$ & $M$ & $S D$ \\
\hline \multicolumn{7}{|l|}{ Self-reported } \\
\hline Helping ${ }^{\mathrm{a}}$ & 2.93 & 0.59 & 2.92 & 0.44 & 3.08 & 0.51 \\
\hline Consideration of others ${ }^{\mathrm{a}}$ & 4.00 & 0.63 & 4.05 & 0.60 & 3.98 & 0.64 \\
\hline Suppression of aggression ${ }^{\mathrm{a}}$ & 3.68 & 0.76 & 3.59 & 0.66 & 3.92 & 0.78 \\
\hline Care orientation ${ }^{\mathrm{b}}$ & 3.59 & 0.69 & 3.63 & 0.72 & 3.60 & 0.77 \\
\hline Social responsibility ${ }^{\mathrm{c}}$ & 3.39 & 0.61 & 3.64 & 0.44 & 3.71 & 0.47 \\
\hline Sympathy & 3.88 & 0.67 & 4.06 & 0.57 & 3.99 & 0.59 \\
\hline Perspective taking ${ }^{\mathrm{d}}$ & 3.62 & 0.69 & 3.68 & 0.64 & 3.72 & 0.71 \\
\hline Social desirability ${ }^{\mathrm{e}}$ & 1.40 & 0.21 & 1.38 & 0.21 & 1.41 & 0.21 \\
\hline \multicolumn{7}{|l|}{ Friend reported } \\
\hline Consideration of others ${ }^{\mathrm{a}}$ & 4.22 & 0.79 & 4.26 & 0.63 & 4.20 & 0.58 \\
\hline Suppression of aggression ${ }^{\mathrm{a}}$ & 4.16 & 0.63 & 4.16 & 0.70 & 4.21 & 0.50 \\
\hline Social responsibility $^{\mathrm{c}}$ & 3.35 & 0.47 & 3.44 & 0.59 & 3.39 & 0.39 \\
\hline Sympathyd & 3.78 & 0.63 & 3.60 & 0.65 & 3.73 & 0.68 \\
\hline Perspective taking ${ }^{\mathrm{d}}$ & 3.35 & 0.72 & 3.09 & 0.72 & 3.19 & 0.64 \\
\hline \multicolumn{7}{|l|}{ Interview moral judgment } \\
\hline Composite score & 292.36 & 41.56 & & & 289.51 & 43.32 \\
\hline Level $1^{\mathrm{f}}$ & 0.13 & 0.12 & & & 0.13 & 0.16 \\
\hline Level 2 & 0.24 & 0.09 & & & 0.24 & 0.08 \\
\hline Level 3 & 0.21 & 0.15 & & & 0.23 & 0.16 \\
\hline Level 4 & 0.31 & 0.18 & & & 0.28 & 0.16 \\
\hline Level 5 & 0.12 & 0.14 & & & 0.12 & 0.12 \\
\hline \multicolumn{7}{|l|}{ PROM moral judgment } \\
\hline Composite score/long form & 194.9 & 11.2 & 196.6 & 9.5 & 193.9 & 8.7 \\
\hline
\end{tabular}

Note. $\mathrm{T}=$ time; $\mathrm{PROM}=$ an objective measure of prosocial moral reasoning.

${ }^{a}$ From Weinberger's Adjustment Inventory (Weinberger, 1991, 1997); scored on a 5-point scale.

${ }^{\mathrm{b}}$ From Penner and Finkelstein (1998); scored on a 5-point scale.

${ }^{\mathrm{c}}$ From Schwartz (1968); adapted by Penner and Finkelstein (1998); scored on a 5-point scale.

${ }^{\mathrm{d}}$ From the Interpersonal Reactivity Index (Davis, 1983); scored on a 5-point scale.

${ }^{\mathrm{e}}$ From Crowne and Marlowe (1964); scored as true/false (1 or 2; 2 = higher social desirability).

${ }^{\mathrm{f}}$ The levels are proportion scores. 
friends' assessments of participants' prosocial dispositions (henceforth labeled the friend prosocial measure). The composite scores were negatively skewed at T10 and T11 and were transformed with square root transformations, although means are presented for nontransformed, individual measures.

\section{Prosocial Moral Reasoning}

Prosocial moral reasoning was assessed with interviews at T10 and T12 and with an objective measure at T10, T11, and T12.

At T10 and T12, participants who were available $(n \mathrm{~s}=28$ at T10 and 32 at T12) were interviewed with the same five moral reasoning stories used in the adolescent follow-ups (see Eisenberg et al., 1987, 1991, 1995). In a typical story, the story protagonist had to choose between practicing swimming for a competition in which he or she likely would win a prize and using that time to teach handicapped children to swim. Story protagonists in four of the stories were specified as being the same sex as the participants; sex was unspecified in one story because the protagonists were a group. Participants were presented with the stories in random order and asked what the story protagonist should do and why. Standard probes were used to encourage participants to elaborate on their reasoning.

Scoring of the prosocial reasoning stories (interviews). Responses first were rated in terms of the extent to which their reasoning reflected each of the categories outlined by Eisenberg et al. (1987, 1991); multiple categories could be coded for each dilemma. Those used with any frequency and relevant to this article were as follows:

1. Hedonistic reasoning - (a) Hedonistic gain to the self (orientation to gain for oneself; e.g., "She might get a reward"), (b) direct reciprocity (orientation to personal gain because of direct reciprocity or lack of reciprocity from the recipient of an act; e.g., "They might return the favor someday"), (c) affectional relationship (orientation to the individual's identification or relationship with another or liking for the other; e.g., "He might be a friend");

2. Needs oriented (orientation to the physical, material, or psychological needs of the other person; e.g., "He needs blood," or "He's sad");

3. Stereotypes of a good or bad person (orientation to stereotyped images of a good or bad person; e.g., "It is the kind thing to do");

4. Approval and interpersonal orientation (orientation to others' approval and acceptance in deciding what is the correct behavior; e.g., "Others would think she did the right thing");

5. Self-reflective empathic orientation - (a) sympathetic orientation (expression of sympathetic concern and caring for others; e.g., "He'd feel sorry for them"), (b) role taking (the individual explicitly takes the perspective of the other or has the story protagonist do so; e.g., "He'd think about how he would feel if he were in that situation"), (c) internalized positive affect related to consequences (orientation to internal positive affect as a result of a particular course of action because of the consequences of one's act for the other person; e.g., "She'd feel good because the children who needed help would walk better"), (d) internalized negative affect related to consequences (the same as Item $\mathrm{c}$ but for negative affect);

6. Internalized affect because of gain (loss) of self-respect due to living up (not living up) to one's values - (a) positive (orientation to feeling good, often about oneself, as a consequence of living up to internalized values; e.g., "She'd feel good about herself because she'd done what she knows is right"), (b) negative (concern with feeling bad as a consequence of not living up to internalized values; e.g., "He'd feel guilty if he didn't help because he didn't live up to his own values");

7. Internalized law, norm, and value orientation (orientation to an internalized responsibility, duty, or need to uphold the laws and accepted norms or values; e.g., "All citizens of a society have a responsibility to help others when they need assistance");

8. Other abstract and/or internalized types of reasoning - (a) generalized reciprocity (orientation to indirect reciprocity in a society, i.e., exchange that is not one to one but eventually benefits all or a larger group; e.g., "If he helps that person, that person will assist others at another time, and everyone is more likely to be helped"), (b) concern with the condition of society (orientation to improving the society or community as a whole; e.g., "It is important to help one another so that the community in general is a better place"), (c) concern with individual rights and justice (orientation to protecting individual rights and preventing injustices that violate another's rights; e.g., "Everyone should have the right to walk down the street without being accosted"), (d) equality of people (orientation to the principle of the equal value of all people; e.g., "All people are of equal worth and thus are worthy of help").

Participants were assigned scores reflecting the frequency with which they used each of the various types of reasoning when discussing both the pros and the cons of helping the needy other in the story dilemma $(0=$ no use of category, $3=$ a major type of reasoning used $)$. Then the scores for each category were summed across the stories. At T10 and $\mathrm{T} 12$, a team of 2 individuals jointly coded all the data for reliability. Interrater reliabilities for $\mathrm{T} 1$ to $\mathrm{T} 9$ are presented in previous articles (e.g., Eisenberg et al., 1987, 1991, 1995). For all time periods, the primary coder was the same person, whereas 11 persons have served as reliability coders over the 12 time periods. To prevent bias in scoring, we ensured that the primary coder as well as 1 reliability coder at T10 and both reliability coders at T12 were unaware of the identity of the children. Coders also had no information regarding participants' scores on the other measures. Interrater reliabilities at T10 (Pearson product-moment correlations) computed for each reasoning category ranged from .68 to .98, with all except pragmatic reasoning being above .72. At T12, all reliabilities were .80 or above, except that the reliability of concern for individual rights and justice was .73 . The equality of people reasoning category was never coded at T12.

As previously noted, the primary coder for the moral reasoning protocols was the same person who had scored the data at all previous follow-ups. We used this procedure to prevent differences across different coders at different times being interpreted as age-related changes in reasoning. To determine whether there was any change in the primary coder's scoring over the years (and to prevent the primary coder from knowing the age of participants being coded), two protocols from each of the T4 to T9 follow-ups were mixed together with the various protocols from $\mathrm{T} 10$ or T12 and were rescored by the primary coder. Scores on the data from earlier sessions were highly similar to the original scores for the same data (agreement on codes within 1 point was $84 \%$ or higher on all categories; correlations were .80 or higher).

The categories of reasoning are viewed as reflecting developmental levels of prosocial moral reasoning; these levels were derived from the results of cross-sectional research (see Eisenberg, 1986; 1979). Briefly, the levels are as follows: Level 1, hedonistic, self-focused orientation; Level 2, needs of others orientation; Level 3, approval and interpersonal orientation and stereotyped orientation; Level 4, self-reflective, empathic orientation; and Level 5, strongly internalized orientation. As at earlier followups, we computed a composite index representing level of moral judgment for each participant at both $\mathrm{T} 10$ and at T12 by weighing the proportion of the participant's reasoning at each level (as indicated by the 0 to 3 ratings for relevant categories summed across stories, divided by the total scores for all categories of reasoning) by the level of reasoning (e.g., 1 for hedonistic, direct reciprocity, or affectional relationship reasoning; 2 for needsoriented reasoning; 3 for stereotypic or approval/interpersonal reasoning; 4 for higher level reasoning; Eisenberg et al., 1987, for more detail). Because it is debatable whether Level 5 is more moral than Level 4 and because scores for these two levels were weighted equally in prior assessments (as well as on the objective measure of moral judgment), scores for Levels 4 and 5 were weighted equally in the analyses presented (although the results did not change much if Level 5 was weighted higher). These proportion scores were multiplied by 100 for presentation. Scores at T10 and T12 were negatively skewed, so log 10 transformations were used (although untransformed means are presented).

The objective measure of prosocial moral judgment (PROM). At $\mathrm{T} 10, \mathrm{~T} 11$, and $\mathrm{T} 12$ (as at T9), participants $(N \mathrm{~s}=32,31$, and 32, respec- 
tively) completed an objective, pencil-and-paper measure of prosocial moral reasoning, the PROM (Carlo et al., 1992; Eisenberg et al., 1995). At T9, participants were mailed a version of the PROM containing six stories, five of which were very similar in content to the vignettes used in the moral reasoning interview. At T10, T11, and T12, participants were sent a similar version designed for adults (including one additional story and nine rather than six responses per story). The PROM is modeled on Rest's (1979) Defining Issues Test; participants are presented with moral dilemmas and then rate the importance of reasons why the protagonist should or should not help the needy other in a given story on a 7 -point scale $(1=$ not at all, $7=$ greatly $)$. At $\mathrm{T} 10$ to $\mathrm{T} 12$, each of the stories included two hedonistic items that pertained to hedonistic or direct reciprocity reasoning (e.g., "It depends how much fun Mary expects the party to be, and what sorts of things are happening at the party"), one needs-oriented item (e.g., "It depends whether the girl really needs help or not"), two approval-oriented items (e.g., "It depends whether Mary's parents and friends will think she did the right or she did the wrong thing"), one stereotypic item (e.g., "It depends if Mary thinks it's the decent thing to do or not), and two items reflecting higher level reasoning (i.e., sympathetic, perspective taking, internalized affect, or abstract internalized reasoning; e.g., "It depends if Ann would feel guilty if the girl is hurt because she did not help"). The ninth reasoning choice was a lie/nonsense item which sounded abstract but did not make sense (e.g., "It depends whether Mary believes in people's values of metacognition or not"). These items were used merely to eliminate participants who scored high on this subscale (although none was eliminated because doing so had virtually no effect on the results). Alphas for the hedonistic, needs-oriented, approval, stereotypic, internalized, and lie scales were $.90, .70, .78, .95, .89$, and .88 , respectively, at $\mathrm{T} 10 ; .89$, $.68, .93, .78, .92$, and .93 , respectively, at $\mathrm{T} 11$; and $.91, .86, .94, .92, .97$, and .86 , respectively, at $\mathrm{T} 12$.

As was done previously with the same or similar measures (Boehnke, Silbereisen, Eisenberg, Reykowski, \& Palmonari, 1989; Carlo et al., 1992) and at T9 (Eisenberg et al., 1995), scores on each of the PROM subscales (using two items per story when appropriate) were averaged across stories and then transformed to proportion scores by dividing each of the PROM subscale scores (for the five types of reasoning) by the sum of the five PROM subscale scores. On the basis of the means in this study and the findings in Carlo et al. (1992) and Eisenberg et al. (1995), a weighted score was computed in which percentage of internalized reasoning was multiplied by 3 , percentages of needs-oriented and stereotypic reasoning were multiplied by 2 , and percentages of hedonistic and approval-oriented reasoning were multiplied by 1 . These weighted values were then summed. This composite score was used in subsequent analyses.

\section{Social Desirability}

To assess social desirability (SD), participants completed 25 true/ false items from an SD scale (Crowne \& Marlowe, 1964; $\alpha$ s $=.86, .85$, and .86 at $\mathrm{T} 10, \mathrm{~T} 11$, and $\mathrm{T} 12$, respectively).

\section{Procedures}

At T10, T11, and T12, participants initially were contacted by phone if possible; then a packet of questionnaires was sent to the participants to fill out and return (order of the PROM and questionnaires was counterbalanced). Participants were asked to supply names and addresses of up to three friends if they were willing to do so when they returned the questionnaires. Friends were sent packets of questionnaires and paid for their participation (see Eisenberg et al., 1987, 1991, 1995, for information about childhood sessions).

At T10 and T12, participants ( $n \mathrm{~s}=28$ at T10 and 32 at T12) were subsequently interviewed on their prosocial moral reasoning, usually at the university. Participants were interviewed individually by a woman who had not been involved in any follow-ups at T9 or earlier. The prosocial dilemmas were presented in random order and involved samesex (or unspecified) protagonists, and a standard sequence of questioning was followed. Participants were paid for both the questionnaires and the interview.

\section{Results}

Means and standard deviations for the major variables at T10 to T12 are presented in Table 1 (means for variables from earlier periods and some for T9 are in Eisenberg et al., 1991, 1995, 1999). A list of the major variables prior to T10 is provided in Table 2. Recall that most of the indices of a prosocial personality were significantly correlated (and loaded on one factor) and were combined into a composite score at each assessment in adulthood, both for self-and friend reports. In initial analyses, we examined evidence for the existence of a prosocial personality as assessed with these composite scores within and across time (and explored issues to do with social desirability). Next, we examined consistency in moral reasoning across time and measures. Then we calculated the relations of measures of moral reasoning to indices of a prosocial disposition. In general, the focus is on T10 to T12 measures in relation to antecedent measures, although relations of T9 PROM data with antecedent (as well as T10 to T12) measures are included because they were not reported in prior publications, and important concurrent patterns are briefly summarized. Two-tailed correlations are reported throughout, although specific hypotheses frequently were formulated. Marginal correlations are discussed only if they are consistent with the larger pattern of findings.

All major correlational relations presented were examined for outliers (of three standard deviations or more) with the regression procedures of SPSS, computed for the two variables involved in each correlation. In very few cases were there outliers, and in most of these, the findings were stronger when the outliers were removed (these findings are indicated in the tables). Moreover, scatter plots were examined for all major findings, and the patterns of relations for significant correlations did not seem to be due to only a small number of cases.

\section{Relations of SD to Moral Judgment and Prosocial Dispositions}

SD scores at T10, T11, and T12 were significantly related to concurrent self-reported prosocial dispositions, $r \mathrm{~s}(30,27$, and 29 , respectively) $=.60, .61$, and $.53, p \mathrm{~s}<.001, .001$, and .002 , but not to the interview moral reasoning scores or the PROM composite scores.

Because of the correlations between SD and some measures, we computed auxiliary partial correlations, controlling for SD, when examining correlations between two self-report measures. Usually, the partial correlations were similar to the zero-order correlations. Thus, zero-order correlations usually are reported, although partial correlations are also noted for key analyses involving self-reported prosociality composite scores.

\section{Relations Between Reporters and Across Time on Measures of a Prosocial Personality}

In general, there were numerous relations among various measures of prosocial functioning, often across reporters. 
Table 2. Correlations of T10, T11, and T12 Self-and Friend-Reported Prosocial Dispositions to Prosocial-Related Measures at Earlier Assessments

\begin{tabular}{|c|c|c|c|c|c|}
\hline \multirow{2}{*}{$\begin{array}{l}\text { Measure of prior prosocial or } \\
\text { empathy-related responding }\end{array}$} & \multicolumn{3}{|c|}{$\begin{array}{r}\text { Self-reported } \\
\text { prosociality }\end{array}$} & \multicolumn{2}{|c|}{$\begin{array}{l}\text { Friend-reported } \\
\text { prosociality }\end{array}$} \\
\hline & T10 & T11 & $\mathrm{T} 12$ & $\mathrm{~T} 10$ & $\mathrm{~T} 12$ \\
\hline \multicolumn{6}{|l|}{ Self-reported helping ${ }^{\mathrm{a}}$} \\
\hline T6 & $\begin{array}{l}.33 \dagger[.29] \\
(.29)\end{array}$ & $\begin{array}{l}.33 \dagger \\
(.17)\end{array}$ & $\begin{array}{c}.40^{*} \\
\left(.36^{*}\right)\end{array}$ & .21 & -.04 \\
\hline $\mathrm{T} 7$ & $\begin{array}{l}.53 * *[.57 * * \\
(.37 *)\end{array}$ & $\begin{array}{l}*] .53 * * \\
(.33 \dagger)\end{array}$ & $\begin{array}{c}.66^{* * *} \\
(.60 * * *)\end{array}$ & .16 & .02 \\
\hline $\mathrm{T} 8$ & $\begin{array}{l}.54 * * * \\
(.54 * *)\end{array}$ & $\begin{array}{l}.54 * * \\
(.60 * * *)\end{array}$ & $\begin{array}{l}.49 * * \\
(.53 * * *)\end{array}$ & $.42 *$ & -.04 \\
\hline \multicolumn{6}{|c|}{ Self-reported prosociality composite ${ }^{\mathrm{b}}$} \\
\hline T9 & $\begin{array}{c}.75^{* * *} \\
(.78 * * *)\end{array}$ & $\begin{array}{l}.64^{* * *} \\
\left(.75^{* * *}\right)\end{array}$ & $\begin{array}{l}.56^{* * *} \\
(.64 * * *)\end{array}$ & $.56^{* *}$ & $.41 *$ \\
\hline \multicolumn{6}{|l|}{ Empathy $^{\mathrm{c}}$} \\
\hline $\mathrm{T} 4$ & $\begin{array}{l}.16 \\
(.11)\end{array}$ & $\begin{array}{c}.39^{*} \\
\left(.39^{*}\right)\end{array}$ & $\begin{array}{l}.27 \\
(.34 \dagger)\end{array}$ & .11 & .07 \\
\hline $\mathrm{T} 5$ & $\begin{array}{c}.46^{* *} \\
\left(.50^{* *}\right)\end{array}$ & $\begin{array}{l}.52 * * \\
\left(.51^{* *}\right)\end{array}$ & $\begin{array}{l}.30 \dagger \\
(.35 \dagger)\end{array}$ & $.47^{*}$ & .10 \\
\hline T6 & $\begin{array}{c}.58 * * * \\
\left(.48^{* *}\right)\end{array}$ & $\begin{array}{c}.68^{* * *} \\
\left(.54^{* *}\right)\end{array}$ & $\begin{array}{l}.67 * * * \\
(.60 * * *)\end{array}$ & $.32 \dagger$ & .24 \\
\hline \multicolumn{6}{|l|}{ Sympathy ${ }^{\mathrm{d}}$} \\
\hline $\mathrm{T} 7$ & $\begin{array}{l}.46^{* *} \\
(.27)\end{array}$ & $\begin{array}{l}.60^{* * *} \\
\left(.46^{*}\right)\end{array}$ & $\begin{array}{l}.54 * * * \\
\left(.47^{* *}\right)\end{array}$ & .18 & $.67 * * *$ \\
\hline $\mathrm{T} 8$ & $\begin{array}{l}.68 * * * \\
(.62 * * *)\end{array}$ & $\begin{array}{l}.75^{* * *} \\
\left(.70^{* * *}\right)\end{array}$ & $\begin{array}{l}.47 * * \\
(.50 * *)\end{array}$ & $.38^{*}$ & .34 \\
\hline \multicolumn{6}{|l|}{ Perspective taking ${ }^{\mathrm{d}}$} \\
\hline $\mathrm{T} 7$ & $\begin{array}{l}.44 * \\
(.23)\end{array}$ & $\begin{array}{l}.50 * * \\
(.42 *)\end{array}$ & $\begin{array}{l}.53^{* *} \\
\left(.49^{* *}\right)\end{array}$ & .09 & -.02 \\
\hline $\mathrm{T} 8$ & $\begin{array}{l}.69 * * * \\
(.65 * * *)\end{array}$ & $\begin{array}{c}.66^{* * *} \\
\left(.68^{* * *}\right)\end{array}$ & $\begin{array}{c}.66^{* *} \\
\left(.70^{* *}\right)\end{array}$ & $.50 * *$ & .17 \\
\hline \multicolumn{6}{|c|}{ Mothers' report of child's helping ${ }^{\mathrm{a}}$} \\
\hline T6 & $.41 *$ & $.49 * *$ & $.44 *$ & .21 & .02 \\
\hline $\mathrm{T} 7$ & $.32 \dagger$ & .22 & .20 & .16 & .00 \\
\hline T8 & $.48 * *$ & $.44^{*}$ & $.46^{* *}$ & $.42 *$ & .18 \\
\hline
\end{tabular}

Note. Correlations in brackets are recomputed correlations, from which an outlier was thrown out. Correlations in parentheses are partial correlations in which we controlled for social desirability. There were no more significant and marginal relations between T11 friend-reported prosociality and other variables than would be expected by chance. $\mathrm{T}=$ time.

${ }^{a}$ On the adapted Rushton et al. (1981) measure.

${ }^{\mathrm{b}}$ This composite score included items from the sympathy, perspective taking, suppression of aggression, consideration for others, care orientation, and social responsibility scales at T10 to T12; at T9, the composite contained items related to the first four scales.

${ }^{\text {c } F r o m ~ B r y a n t ' s ~(1982) ~ e m p a t h y ~ s c a l e . ~}$

${ }^{\mathrm{d}}$ From Davis's (1983) Interpersonal Reactivity Index.

${ }^{\mathrm{e}}$ This composite score included items from sympathy, perspective taking, consideration for others, suppression of aggression, and social responsibility at $\mathrm{T} 10$ to $\mathrm{T} 12$.$$
\dagger p<.10 . \quad * p<.05 . \quad * * p<.01 . \quad * * * p<.001 .
$$

Relations of Friends' Reports to Participants' Reports of Prosocial Traits at T10 to T12

Friend-and self-reported prosocial dispositions (the composite scores) were at least marginally positively related at T10 (21-22 years), T11 (23-24 years), and T12 (25-26 years), rs (26, 22, and 21 , respectively) $=.66, .35$, and $.56, p \mathrm{~s}<.001, .10$, and .001 . These relations held even though the measures of a prosocial disposition differed somewhat for friends and participants. Moreover, across time, T10 to T12 self-and friend-reported prosocial composite scores correlated with one another at $p<.075$ or better $(r \mathrm{~s}=$ .37 to .48 ; average $r=.41$ ).

\section{Consistency of Prosocial Dispositions Across Time}

In general, T10, T11, and T12 measures of a prosocial disposition were correlated not only among themselves but also with many similar measures obtained at younger ages.

Self-reported prosocial dispositions. Self-reported prosocial dispositions were significantly correlated across time at T10, T11, and T12; correlations ranged from .77 to $.81, p \mathrm{~s}<.001$ (correlations ranged from .66 to .75 when we controlled for SD at any of the relevant assessments). Self-reported prosociality at T10 to T12 also was related to earlier self-reports of similar prosocial tendencies. As can be seen in Table 2, there were many more significant cor- 
relations than would be expected by chance between T10 to T12 prosocial dispositions and self-reported prosociality/helping, empathy, sympathy, and perspective taking in late childhood and adolescence. Thirty-four of 42 zero-order correlations between selfreported prosociality and measures of prosociality at younger ages were significant at $p<.05$, two-tailed. Correlations between T10, $\mathrm{T} 11$, or T12 prosocial personality and self-reported helping at T6 to T8 ranged from .33 to .66 (seven of nine were significant; average correlation for the nine correlations $=.48$ ); those between T10, $\mathrm{T} 11$, or T12 prosocial dispositions and empathy at younger ages ranged from .16 to .68 , with all but two being .30 or higher (average $r=.45$; six of nine were significant). Analogous correlations for sympathy ranged from .46 to .75 (average $r=.58$; all were significant); those for perspective taking ranged from .44 to .69 (average $r=.58$; all were significant); and those for mother-reported helping ranged from .20 to .49 (average $r=.38$, with six of the nine correlations being .41 or higher and significant). The correlations changed relatively little when SD was controlled.

It also is notable that individual measures of self-reported prosociality were nearly always substantially related to the same or similar measures from up to 16 years earlier. For example, reports of helping at T10, T11, or T12 on a short version of Rushton et al.'s (1981) scale were significantly related to reports on the longer version of the scale at T6, T7, and T8, correlations ranged from .41 to .66 (average $r=.52$ ), $p$ s $<.02$ or better. Similarly, sympathy scores on the IRI at T10, T11, and T12 were positively related to empathy on Bryant's (1982) scale at T5 (age 11-12), with correlations ranging from .47 to .59 (average $r=54$ ), $p$ s $<.007$ or better, and at T6 (age 12-13), with correlations ranging from .59 to .74 (average $r=.66$ ), $p$ s $<.001$. Sympathy at T11 also was related to reported empathy at T4 (9-10 years), $r(29)=.49, p<$ .005 . Further, all correlations between the measures of sympathy at $\mathrm{T} 10, \mathrm{~T} 11$, or $\mathrm{T} 12$ and those at $\mathrm{T} 7, \mathrm{~T} 8$, and $\mathrm{T} 9$ were significant and ranged from .47 to .81 (average $r=.62$; sometimes there was an outlier, but removing it only strengthened the correlations). Similarly, correlations of measures of perspective taking at T10, T11, or T12 with those at T7 through T9 were all substantial (at least .44, usually .52 to .75 ; average $r=.62$ ). These relations changed relatively little when we controlled for SD. Thus, there was clear evidence of intraindividual consistency in prosocial dispositions over time. In addition, self-reported prosocial dispositions at T10, T11, and T12 were significantly correlated with mothers' reports of children's prosocial behavior at T6 and T8 (see Table 2).

In Eisenberg et al. (1999), relations of observed preschool prosocial behavior with $\mathrm{T} 10$ and $\mathrm{T} 11$ prosocial dispositions were reported (no other T10 or T11 data have been reported). Thus, we examine only findings for $\mathrm{T} 12$ in relation to $\mathrm{T} 1$ prosocial behavior. Consistent with prior findings (although the correlation was only marginally significant at T11), self-reported prosociality was positively related to observed preschool spontaneous sharing, $r(30)=$ $.37, p<.037$. Unexpectedly, it also was positively related to compliant sharing, $r(30)=.37, p<.036$.

Friends' reports of prosocial dispositions at T10 to T12. Friends' reports of participants' prosocial dispositions at T10 were related to a number of earlier measures of prosocial and empathy-related responding, especially those from T8 and later. Recall that friend data were not available for a minority of participants and that the sample sizes for these analyses were small. Even with the small sample size for friend-report data, 8 of 42 possible correlations were sig- nificant at $p<.05$, two-tailed, when just over 1 correlation would be expected to be in the hypothesized direction by chance. T10 friend-reported prosocial dispositions were correlated with selfreported prosocial behavior at $\mathrm{T} 8$ and the self-reported prosocial composite at T9, self-reported empathy at T5, sympathy and perspective taking at T8, and mothers' reports of children's helping at T8 (these correlations ranged from .38 to .56; see Table 2). Fewer relations were obtained for T12 friend reports, perhaps because of the smaller sample size (23 friends); nonetheless, friends' reports were significantly related to self-reported sympathy at $\mathrm{T} 7$ and to the participant-reported prosocial composite score at T9. Although a number of the correlations of friends' report of a prosocial disposition at T11 with earlier measures of a prosocial disposition were positive and above .20 , none was significant. ${ }^{1}$

Relations between friend-reported prosociality at T10 or T11 and preschool prosocial behavior are reported in Eisenberg et al. (1995) and were nonsignificant. However, consistent with T12 selfreports, T12 friends' reports of prosociality were marginally positively related to spontaneous sharing in preschool, $r(21)=.35, p$ $<.099 .^{2}$

\section{Moral Reasoning: Consistency Across Time and Measures}

Relations among scores on the interview and objective measures of moral judgment were examined contemporaneously and across time.

Consistency over time within type of measure. T10 and T12 moral reasoning composites were significantly related with one another, $r(26)=.64, p<.001$, as well as with the T9 interview composite score, $r \mathrm{~s}(22$ and 26 , respectively) $=.48$ and $.39, p \mathrm{~s}<.016$ and .038 . Moral reasoning at T10 or T12 was not significantly related to reasoning in adolescence (at $\mathrm{T} 7$ or $\mathrm{T} 8$ ), with the exception of a significant relation between reasoning at $\mathrm{T} 7$ and at $\mathrm{T} 12$, $r(30)=.35, p<.048$. Thus, interview moral reasoning scores tended to be somewhat consistent over the 6 years in early adulthood but generally were not related to analogous interview scores in adolescence.

Even though the T9 PROM contained one less story and fewer items, T9 PROM scores were substantially related to scores at T10, $\mathrm{T} 11$, and $\mathrm{T} 12, r \mathrm{~s}(30,29$, and 30 , respectively $)=.71, .72$, and .51 , ps $<.001, .001$. and .003. Moreover, T10, T11, and T12 PROM

\footnotetext{
${ }^{1}$ When individual T12 friend measures (instead of the composite) were related to the same variables as reported by participants, the number of significant relations was higher. For example, friends' reports of participants' sympathy at T12 were related to participants' self-reported sympathy at $\mathrm{T} 6$ through $\mathrm{T} 9, r \mathrm{~s}(14,21,20$, and 21 , respectively) $=.59$, $.76, .53$, and $.46, p$ s $<.015, .001, .011$, and .028 .

${ }^{2}$ At T4 and T5 children had an opportunity to donate part of their payment to charity (see Eisenberg et al., 1987); these donations at T4 were marginally related to $\mathrm{T} 10$ prosocial dispositions, $r(30)=.32$, $p<.079$. Children also had an opportunity to help the experimenter at $\mathrm{T} 6, \mathrm{~T} 7$, and $\mathrm{T} 8$ by filling out additional questionnaires at home (Eisenberg et al., 1991); such helping at T6 was related to prosocial dispositions at $\mathrm{T} 10, \mathrm{~T} 11$, and $\mathrm{T} 12, r \mathrm{~s}(30)=.47, .43$, and $.38, p \mathrm{~s}<.005, .015$, and .031. Moreover, friend-reported prosocial dispositions at T10 were positively related to donations at $\mathrm{T} 4, r(26)=.41, p<.032$. The findings for friends' reports were not much more than would be expected by chance, and moral reasoning was not related to donating or helping at above chance levels.
} 
scores were highly interrelated: Correlations ranged from .50 between T11 and T12 to .76 between T10 and T11 (average $r=.63$ ). Thus, there was interindividual consistency in level of performance on the PROM over the 6 years from T9 to T12.

Consistency of moral reasoning across measures. As at $\mathrm{T} 9$ (Eisenberg et al., 1995), at T10 and T12 there were significant correlations between concurrent PROM and interview moral reasoning composite scores (recall there was no moral reasoning interview at $\mathrm{T} 11), r \mathrm{~s}(26$ and 29 , respectively) $=.53$ and $.41, p \mathrm{~s}<.004$ and .021 , as well as some significant relations between the two measures across time in adulthood. In addition, T10 PROM scores were significantly related to interview moral reasoning composite scores at $\mathrm{T} 9$ and $\mathrm{T} 8, r \mathrm{~s}(26$ and 30 , respectively) $=.52$ and $.41, p \mathrm{~s}$ $<.005$ and .018 , whereas T11 PROM scores were significantly correlated with interview composite scores at $\mathrm{T} 9$ and $\mathrm{T} 7, r \mathrm{~s}(25$ and 29 , respectively) $=.52$ and $.38, p \mathrm{~s}<.005$ and .036 (and $p<.06$ for T8). T12 PROM scores were not significantly related to moral interview scores prior to $\mathrm{T} 10$.

\section{The Relation of Moral Reasoning to Prosocial Dispositions}

Scores for both interview and PROM measures of moral judgment were correlated with some measures of prosociality, often over numerous years.

The relation of moral reasoning to self-reported prosocial dispositions. Five measures of moral reasoning initially were correlated with indices of a prosocial personality. For the T10 and
T12 interview moral reasoning data, results were computed for the composite score as well as for the type of reasoning most frequently associated with moral behavior in past assessments, Level 1 self-oriented reasoning (Eisenberg, 1986; Eisenberg et al., 1991, 1995). However, at T12, findings for these two measures were highly similar (albeit reversed), so only correlations with the composite score are presented. Because findings for PROM scores at T9 to T12 were similar, to reduce the number of correlations we standardized PROM scores for these four assessments and averaged them to form a composite score for use in the analyses. Only zero-order correlations between the moral judgment measures and the self-reported prosociality composite scores are presented because controlling for SD had little effect on the pattern of relations (SD was unrelated to these measures of moral reasoning).

The PROM composite score was significantly correlated with self-reported prosocial dispositions at $\mathrm{T} 9$ to $\mathrm{T} 12$, empathy at $\mathrm{T} 6$, and sympathy at T7 and T8 (average $r=.43 ; 9$ of 12 correlations in Table 3 were significant). With regard to the moral interview, moral reasoning at T10 tended to be related to self-reported prosociality in adulthood, especially for self-oriented reasoning (average $r=-.39$ for self-oriented reasoning, with three of the four correlations being significant; average correlations for the T10 composite $=.22, n s$ ). The T12 interview composite also usually was positively related to self-reported prosociality in adulthood (average $r=.39$, with three of four latter correlations being significant). Further, there were numerous relations between measures of inter-

Table 3. Correlations of Interview Prosocial Moral Reasoning Scores at T10 and T12 With Measures of a Prosocial Disposition in Adulthood and Empathy/Sympathy in Childhood and Adolescence

\begin{tabular}{|c|c|c|c|c|}
\hline \multirow[b]{3}{*}{ Measure of prosociality } & \multicolumn{4}{|c|}{ Measure of prosocial moral judgment } \\
\hline & \multicolumn{2}{|c|}{$\mathrm{T} 10$} & \multirow[b]{2}{*}{ T12 composite } & \multirow{2}{*}{$\begin{array}{c}\text { T9 to T12 } \\
\text { PROM composite }\end{array}$} \\
\hline & Composite & Self-oriented & & \\
\hline \multicolumn{5}{|c|}{ Self-report prosocial composite } \\
\hline T9 & .26 & $-.44 *$ & $.30 \dagger$ & $.54 * * *(.72)^{* * *}$ \\
\hline $\mathrm{T} 10$ & .30 & $-.42 *$ & $.37^{*}$ & $.50 * *(.73 * * *)$ \\
\hline T11 & .20 & $-.43 *$ & $.37 *$ & $.42 *(.66 * * *)$ \\
\hline $\mathrm{T} 12$ & .11 & -.25 & $.52 * *$ & $.39 *$ \\
\hline \multicolumn{5}{|c|}{ Friend-report prosocial composite ${ }^{b}$} \\
\hline $\mathrm{T} 10$ & $.34 \dagger$ & $-.43 *$ & $.26(.37 *)$ & $.39 *$ \\
\hline $\mathrm{T} 11$ & .08 & -.09 & .15 & .11 \\
\hline T12 & $.43^{*}$ & $-.43 *$ & $.53 * *$ & $.50^{*}$ \\
\hline \multicolumn{5}{|l|}{ Self-report empathy ${ }^{\mathrm{c}}$} \\
\hline $\mathrm{T} 4$ & $.39 *$ & $-.50 * *$ & .27 & .19 \\
\hline T5 & .12 & $-.32 \dagger\left(-.45^{*}\right)$ & .08 & $.30 \dagger$ \\
\hline T6 & .11 & $-.34 \dagger\left(-.49^{* *}\right)$ & $.48 * *$ & $.44^{* *}$ \\
\hline \multicolumn{5}{|l|}{ Self-report sympathyd } \\
\hline $\mathrm{T} 7$ & $.43^{*}$ & $-.55 * *$ & $.54 * *$ & $.49^{* *}$ \\
\hline $\mathrm{T} 8$ & $.40^{*}$ & $-.63 * * *$ & $.32 \dagger$ & $.57 * * *$ \\
\hline
\end{tabular}

Note. Correlations in parentheses are the correlations after we dropped an outlier. Controlling for social desirability had relatively little effect on the correlations. $\mathrm{T}=$ time; $\mathrm{PROM}=$ an objective measure of prosocial moral reasoning.

${ }^{a}$ This composite score included items from sympathy, perspective taking, suppression of aggression, consideration for others, care orientation, and social responsibility scales at T10 to T12; at T9, the composite contained items related to the first four scales.

${ }^{\mathrm{b}}$ This composite score included items from sympathy, perspective taking, consideration for others, suppression of aggression, and social responsibility at T10 to T11; items from the first four scales were included at T9.

' From Bryant's (1982) empathy scale. d From Davis's (1983) Interpersonal Reactivity Index.

$\dagger p<.10 . \quad * p<.05 . \quad * * p<.01 . \quad * * * p<.001$. 
view prosocial moral judgment and measures of sympathy or empathy at younger ages, including some with empathy reported at age $9-10$ or 10-11. Five of nine correlations with measures of T4, $\mathrm{T} 5$, or T6 self-reported empathy were significant (dropping outliers increased the significance of two correlations; average correlation for all correlations $=.32$; absolute values of all correlations ranged from .08 to .50 ; significant correlations ranged from .39 to .50 ), and five of six were significant with $\mathrm{T} 7$ and T8 sympathy (average $r=.48$; absolute values of correlations ranged from .32 to $.63)$. Thus, moral reasoning in adulthood was predicted by empathy/sympathy at younger ages.

Although they are not presented in detail, there also were some significant correlations in the predicted direction between moral reasoning (the four scores in Table 3) and self-reported helping and perspective taking at younger ages (especially T8); however, these findings were not as frequent as those for empathy and sympathy. Three of 12 correlations between measures of moral judgment and self-reported helping at T6 to T8 were significant at $p<.06$ or better (absolute values of significant correlations ranged from .35 to .42 ), and 2 of 8 correlations for T7 or T8 perspective taking were significant (absolute values were .35 and .36), all in the expected direction (and there were more significant relations if self-oriented interview moral reasoning at T12 was considered). The only relation of moral judgment to mothers' reports of prosocial behavior (T6 to T8) was for the composite PROM score with T7 mother-reported helping, $r(25)=.40, p<.036$.

Friends' reports of a prosocial disposition. Seven of eight correlations between measures of moral judgment at T10 and T12 and friends' reports of prosociality at T10 and T12 were significant (absolute values of the correlations ranged from .34 to .53 when we dropped an outlier; average absolute value of $r=.43$; see Table 3). Consistent with the lack of significant relations between T11 friend-reported prosociality and other measures of prosociality, T11 friends' reports of participants' prosocial dispositions were not significantly related measures of moral judgment (see Table 3). ${ }^{3}$

Observed prosocial behavior in preschool. T10 interview moral reasoning composite and self-oriented scores as well as PROM scores at T9 to T11 were unrelated to prosocial behavior in preschool. Unexpectedly, at T12, both the composite interview and the PROM scores were positively related to compliant sharing in preschool, $r(30)=.43$ and $.42, p s<.015$ and .016 , respectively. ${ }^{4}$

\section{Discussion}

The results of this study strongly support the view that there is a prosocial personality disposition, at least in middle-class individuals in Western culture. Various aspects of prosocial responding, such as reported helping, prosocial values and attitudes, and sympathy, were not only intercorrelated, but the aggregate measures of self-reported prosocial responding in adulthood generally were related with friends' concurrent reports of a prosocial orientation and with prosocial markers obtained at younger ages. Specifically, selfreported prosocial dispositions at ages $21-22$ to $25-26$ often related to self-reports of empathy, sympathy, and prosocial behavior, even 10 to 16 years earlier. Moreover, some measures of self-reported prosociality were correlated with mothers' reports of their children's helping behavior in adolescence as well as with friends' reports of prosocial dispositions 2 or 4 years prior or subsequent. Friends' reports of participants' prosocial dispositions at T10 and T12 were also related to some measures of a prosocial disposition years earlier (up to 10 years earlier for empathy). Further, self-reported prosocial dispositions and prosocial moral reasoning on the objective measure of moral judgment (the PROM) were positively related to prosocial behavior when the participants were observed as preschoolers. Thus, these data provide some of the strongest evidence available that prosocial dispositions emerge by late childhood and are relatively stable into adulthood. They also indicate that the seeds of a prosocial disposition can be found in early childhood. Further, the across-reporters findings, along with those found in other studies (e.g., Eisenberg et al., 1987; Penner et al., 1995), provide some evidence of the validity of self-report measures of prosocial dispositions.

The associations between the preschool measures of real-life prosocial behavior and indices of prosocial functioning in adulthood are especially intriguing. As predicted, self-and friend reports of a prosocial personality in adulthood were positively related to preschool spontaneous sharing - the type of prosocial behavior that appears most likely to reflect other-oriented motivation in the preschool context (Eisenberg et al., 1981; Eisenberg et al., 1999). Unexpectedly, however, T12 self-reported prosocial dispositions and T12 moral reasoning on both measures also were positively associated with requested (compliant) sharing in preschool. Although sharing (undifferentiated) has been linked to preschoolers' sympathy (Eisenberg et al., 1988), preschool compliant prosocial behavior (including compliant sharing) generally has been unrelated to young children's moral reasoning or inconsistently (albeit sometimes) related to prosocial tendencies in adolescence (Eisenberg et al., 1999; Eisenberg-Berg \& Hand, 1979). Perhaps children who engage in compliant sharing do not do so for sympathy-related reasons yet develop a self-conception of themselves

${ }^{3}$ Self-reported personal distress (the tendency to feel unease and discomfort in tense interpersonal settings involving others' needs or emotions; $\alpha$ s at $\mathrm{T} 10$ to $\mathrm{T} 12=.76, .66$, and .84 ) also was reported by participants at numerous assessments. Self-reported prosociality at T10 was negatively related to personal distress at $\mathrm{T} 12, r(30)=-.42, p<.015$; T11 prosociality was negatively related to personal distress at T9, T11, and $\mathrm{T} 12 ; r \mathrm{~s}(29)=-.38,-.39$, and $-.44, p \mathrm{~s}<.036, .028$, and .014 , respectively; and T12 prosociality was negatively related to personal distress at $\mathrm{T} 11$ and $\mathrm{T} 12$; correlations ranged from -.35 to $-.44, p \mathrm{~s}<.055$ or better. However, all of these correlations became nonsignificant when SD was controlled in partial correlations. Friend-reported prosociality at T11 (but not T10 or T12) was significantly negatively related to self-reported personal distress at T11 and T12. Personal distress was infrequently related to measures of prosocial moral judgment, and those correlations that were significant were nonsignificant when SD was partialed.

${ }^{4}$ Years of education and marital status at T12 were not related to prosocial reasoning or dispositions. Individuals who were still in college (including graduate school) at T12 (age 25-26) scored somewhat lower in self-rated prosociality than did individuals who were not in college (or who had not gone to college), $r(20)=-.38, p<.033$ (point biserial correlation). However, the fact that T12 college students also were rated lower by friends in prosociality at T11, whereas being in school at T11 was unrelated to T11 prosociality, suggests that it was not the college experience but something about the individuals who had not finished school by $\mathrm{T} 12$ that was associated with lower prosocial disposition scores. 
as prosocial individuals. This self-perception may solidify in adulthood, when people are likely to become involved in close relationships or working relationships that provide many possibilities for sharing in response to legitimate requests or cues from others (e.g., preschoolers who were high in compliant prosocial behavior were targets of peer requests; Eisenberg et al., 1981).

It is likely that the stability in markers of a prosocial disposition is due to a number of factors. These probably include temperamental and/or genetic contributions to empathy-related responding (e.g., Hoffman, 1981; Zahn-Waxler et al., 1992). Moreover, shared rearing environmental influences (Krueger et al., 2001), including parental child-rearing practices (Koestner et al., 1990), may contribute to interindividual stability in prosocial tendencies. Although it is unclear to what degree constitutional and environmental factors contribute to consistency in prosocial tendencies, it appears that stable individual differences in empathy-related responding emerge by childhood and likely account for some consistency over time.

Another interesting finding was that the cognitions about prosocial behaviors, as reflected in prosocial moral reasoning, were related to concurrent and temporally distal measures of a prosocial personality. Specifically, both PROM and interview prosocial moral judgment scores tended to be related to the self-reported and friend-reported prosocial disposition scores in adulthood and to empathy and sympathy years prior. This pattern of findings is consistent with theoretical assertions linking prosocial moral judgment with individual differences in perspective taking, sympathy, and moral behavior. The continuity in the association between prosocial moral judgment and prosocial responding in late adolescence and into adulthood in this study is consistent with the notion that otheroriented cognitions and emotions may foster prosocial moral judgment and vice versa (Eisenberg, 1986; Hoffman, 1987). Indeed, it is likely that, with age, the motives and values reflected in individuals' moral judgment increasingly become a component of their prosocial dispositions (or lack thereof). As people's moral reasoning becomes more value-based and/or grounded in mature perspective taking, it is reasonable to expect moral judgment to become intimately bound to prosocial emotions (e.g., sympathy) and actions as well as to other prosocial cognitions (e.g., cognitions regarding ascription of responsibility; see Hoffman, 2000).

It is noteworthy that prosocial moral judgment was related not only to self-reported prosocial dispositions but also, to some degree, to friends' ratings of participants' prosociality. This finding provides additional evidence that moral judgment contributes in some manner to a prosocial disposition in adulthood. However, it is unclear why friends' ratings at T11 (age 23-24) were not related to prosocial moral judgment, either on the concurrent PROM or on the moral interview administered 2 years prior or subsequent, or to measures of prosocial responding at $\mathrm{T} 9$ or before. The fact that friends' reports of prosociality at $\mathrm{T} 10$ and $\mathrm{T} 12$ but not at $\mathrm{T} 11$ were related to reasoning on the PROM at T11 suggests that the friends who provided reports on participants' prosocial dispositions at T11 may not have been reliable reporters. This prior hypothesis is strengthened by the finding that friends' reports at T10 and T12 but not T11 frequently were correlated with earlier empathy-related and prosocial measures. It is possible that the friends at T11, many of whom had known the participants for a long period of time, had had insufficient recent contact with the participants to make accurate assessments. The transition out of college for a number of the participants may have disconnected them from college friends who had interacted with them on a frequent basis while they were in school (only 9 of the 48 friends at T11 were also raters at T10, and only 17 of the T11 friends were also raters at T12). Alternatively, the study participants may have been going through temporary transitions at age 23-24 that affected their behavior, especially as viewed by others.

In summary, the results of this study support the conclusions that there are individual differences in prosocial dispositions and that these differences clearly emerge by adolescence and are somewhat stable into adulthood. In many instances, the patterns of correlations across time and measures was consistent and of moderate magnitude (significant correlations ranged from approximately .35 to over .70). Moreover, the findings suggest that prosocial moral judgment plays a role in adults' prosocial tendencies and is related to empathy-related responding at younger ages. However, it should be noted that the sample in this study is small and homogenous. Although we examined for outliers, the findings must be viewed as tentative and may not be generalizable to different socioeconomic or racial/ethnic groups. It is possible that less stability would be noted in a lower socioeconomic sample because of the instability of the participants' life circumstances. Nonetheless, given that many of the findings were obtained despite a small sample size and limited power, it is likely that a number of the correlational findings will be replicated in larger samples.

\section{References}

Bar-Tal, D., \& Raviv, A. (1979). Consistency in helping-behavior measures. Child Development, 50, 1235-1238.

Batson, C. D. (1991). The altruism question. Hillsdale, NJ: Erlbaum.

Batson, C. D., Bolen, M. H., Cross, J. A., \& Neuringer-Benefiel, H. E. (1986). Where is the altruism in the altruistic personality? Journal of Personality and Social Psychology, 50, 212-220.

Bergeman, C. S., Chipuer, H., Plomin, R., Pedersen, N. L., McClearn, G. E., \& Nesselroade, J. R. (1993). Genetic and environmental effects on openness to experience, agreeableness, and conscientiousness: An adoption/twin study. Journal of Personality, 61, 159-180.

Block, J., \& Block, J. H. (1973, January). Ego development and the provenance of thought: A longitudinal study of ego and cognitive development in young children. Washington, DC: National Institute of Mental Health.

Boehnke, K., Silbereisen, R. K., Eisenberg, N., Reykowski, J., \& Palmonari, A. (1989). The development of prosocial motivation: A cross-national study. Journal of Cross Cultural Psychology, 20, 219-243.

Bryant, B. K. (1982). An index of empathy for children and adolescents. Child Development, 53, 413-425.

Carlo, G., Eisenberg, N., \& Knight, G. P. (1992). An objective measure of adolescents' prosocial moral reasoning. Journal of Research on Adolescence, 2, 331-349.

Colby, A., \& Kohlberg, L. (1987). The measurement of moral judgment. Cambridge, England: Cambridge University Press.

Colby, A., Kohlberg, L., Gibbs, J., \& Lieberman, M. (1983). A longitudinal study of moral judgment. Monographs of the Society for Research in Child Development, 48, 1-124. 
Crowne, D. P., \& Marlowe, D. (1964). The approval motive. New York: Wiley.

Davis, M. H. (1983). Measuring individual differences in empathy: Evidence for a multidimensional approach. Journal of Personality and Social Psychology, 44, 113-126.

Davis, M. H. (1994). Empathy: A social psychological approach. Madison, WI: Brown \& Benchmark.

Davis, M. H., \& Franzoi, S. (1991). Stability and change in adolescent self-consciousness and empathy. Journal of Research in Personality, 25, 70-87.

Eisenberg, N. (1986). Altruistic emotion, cognition and behavior. Hillsdale, NJ: Erlbaum.

Eisenberg, N., Cameron, E., Tryon, K., \& Dodez, R. (1981). Socialization of prosocial behavior in the preschool classroom. Developmental Psychology, 17, 773-782.

Eisenberg, N., Carlo, G., Murphy, B., \& Van Court, P. (1995). Prosocial development in late adolescence: A longitudinal study. Child Development, 66, 911-936.

Eisenberg, N., \& Fabes, R. A. (1998). Prosocial development. In W. Damon (Series Ed.) \& N. Eisenberg (Vol. Ed.), Handbook of child psychology: Vol. 3. Social, emotional, and personality development (5th ed., pp. 701-778). New York: Wiley.

Eisenberg, N., Fabes, R. A., Karbon, M., Murphy, B. C., Wosinski, M., \& Polazzi, L. (1996). The relations of children's dispositional prosocial behavior to emotionality, regulation, and social functioning. Child Development, 67, 974-992.

Eisenberg, N., Fabes, R. A., Murphy, B., Karbon, M., Maszk, P., \& Smith, M. (1994). The relations of emotionality and regulation to dispositional and situational empathy-related responding. Journal of Personality and Social Psychology, 66, 776-797.

Eisenberg, N., Fabes, R. A., Murphy, B., Karbon, M., Smith, M., \& Maszk, P. (1996). The relations of children's dispositional empathy-related responding to their emotionality, regulation, and social functioning. Developmental Psychology, 32, 195-209.

Eisenberg, N., Guthrie, I. K., Murphy, B. C., Shepard, S. A., Cumberland, A., \& Carlo, G. (1999). Consistency and development of prosocial dispositions: A longitudinal study. Child Development, 70, 1360-1372.

Eisenberg, N., McCreath, H., \& Ahn, R. (1988). Vicarious emotional responsiveness and prosocial behavior: Their interrelations in young children. Personality and Social Psychology Bulletin, 14, 298-311.

Eisenberg, N., Miller, P. A., Shell, R., McNalley, S., \& Shea, C. (1991). Prosocial development in adolescence: A longitudinal study. Developmental Psychology, 27, 849-857.

Eisenberg, N., \& Shell, R. (1986). The relation of prosocial moral judgment and behavior in children: The mediating role of cost. Personality and Social Psychology Bulletin, 12, 426-433.

Eisenberg, N., Shell, R., Pasternack, J., Lennon, R., Beller, R., \& Mathy, R. M. (1987). Prosocial development in middle childhood: A longitudinal study. Developmental Psychology, 23, 712-718.

Eisenberg, N., Zhou, Q., \& Koller, S. (2001). Brazilian adolescents' prosocial moral judgment and behavior: Relations to sympathy, perspective taking, gender-role orientation, and demographic characteristics. Child Development, 72, 518-534.

Eisenberg-Berg, N. (1979). The development of children's prosocial moral judgment. Developmental Psychology, 15, 128-137.

Eisenberg-Berg, N., \& Hand, M. (1979). The relationship of pre- schooler's reasoning about prosocial moral conflicts to prosocial behavior. Child Development, 50, 356-363.

Emde, R. N., Plomin, R., Robinson, J., Corley, R., DeFries, J., \& Fulker, D. W. (1992). Temperament, emotion, and cognition at fourteen months: The MacArthur Longitudinal Twin Study. Child Development, 63, 1437-1455.

Epstein, S. (1979). The stability of behavior: I. On predicting most of the people most of the time. Journal of Personality and Social Psychology, 37, 1097-1126.

Garmon, L. C., Basinger, K. S., Gress, V. R., \& Gibbs, J. C. (1996). Gender differences in stage and expression of moral judgment. Merrill-Palmer Quarterly, 42, 418-437.

Gergen, K. J., Gergen, M. M., \& Meter, K. (1972). Individual orientations to prosocial behavior. Journal of Social Issues, 28, $105-130$.

Gilligan, C., \& Attanucci, J. (1988). Two moral orientations: Gender differences and similarities. Merrill Palmer Quarterly, 34, 223-238.

Graziano, W. G., \& Eisenberg, N. H. (1997). Agreeableness: A dimension of personality. In R. Hogan, J. Johnson, \& S. Briggs (Eds.), Handbook of personality psychology (pp. 795-824). San Diego, CA: Academic Press.

Hoffman, M. L. (1981). Is altruism part of human nature? Journal of Personality and Social Psychology, 40, 121-137.

Hoffman, M. L. (1982). Development of prosocial motivation: Empathy and guilt. In N. Eisenberg (Ed.), The development of prosocial behavior (pp. 281-313). New York: Academic Press.

Hoffman, M. L. (1987). The contribution of empathy to justice and moral judgment. In N. Eisenberg \& J. Strayer (Eds.), Empathy and its development (pp. 47-80). Cambridge, England: University of Cambridge Press.

Hoffman, M. L. (2000). Empathy and moral development: Implications for caring and justice. Cambridge, England: Cambridge University Press.

Janssens, J. M. A. M., \& Dekovic, M. (1997). Child rearing, prosocial moral reasoning, and prosocial behaviour. International Journal of Behavioral Development, 20, 509-527.

Kestenbaum, R., Farber, E. A., \& Sroufe, L. A. (1989). Individual differences in empathy among preschoolers: Relation to attachment history. In N.Eisenberg (Ed.), New directions for child development: Vol. 44. Empathy and related emotional responses (pp. 51-64). San Francisco: Jossey-Bass.

Koestner, R., Franz, C., \& Weinberger, J. (1990). The family origins of empathic concern: A 26-year longitudinal study. Journal of Personality and Social Psychology, 58, 709-717.

Kohlberg, L. (1981). The philosophy of moral development: Moral stages and the idea of justice. San Francisco: Harper and Row.

Kohlberg, L., \& Candee, D. (1984). The relationship of moral judgment to moral action. In W. M. Kurtines \& J. L. Gewirtz (Eds.), Morality, moral behavior, and moral development (pp. 52-73). New York: Wiley.

Krueger, R. F., Hicks, B. M., \& McGue, M. (2001). Altruism and antisocial behavior: Independent tendencies, unique personality correlates, distinct etiologies. Psychological Science, 12, 397-402.

Larrieu, J., \& Mussen, P. (1986). Some personality and motivational correlates of children's prosocial behavior. Journal of Genetic Psychology, 147, 529-542. 
Loehlin, J. C., \& Nichols, R. C. (1976). Heredity, environment, and personality. Austin: University Of Texas Press.

Penner, L. A. (in press). Dispositional and organizational influences on sustained volunteerism: An interactionist perspective. Journal of Social Issues.

Penner, L. A., Escarraz, J., \& Ellis, B. B. (1983). Sociopathy and helping: Looking out for number one. Academic Psychology Bulletin, 5, 195-209.

Penner, L. A., \& Finkelstein, M. A. (1998). Dispositional and structural determinants of volunteerism. Journal of Personality and Social Psychology, 74, 525-537.

Penner, L. A., Fritzsche, B. A., Craiger, J. P., \& Freifeld, T. S. (1995). Measuring the prosocial personality. In J. Butcher \& C. D. Spielberger (Eds.), Advances in personality assessment (Vol. 10, pp. 147-163). Hillsdale, NJ: Erlbaum.

Piliavin, J. A., Dovidio, J. F., Gaertner, S. L., \& Clark, R. D., III. (1981). Emergency intervention. New York: Academic Press.

Rest, J. R. (1979). Development in judging moral issues. Minneapolis: University of Minnesota Press.

Rholes, W. S., \& Bailey, S. (1983). The effects of level of moral reasoning in consistency between moral attitudes and related behaviors. Social Cognition, 2, 32-48.

Rothbart, M. K., Ahadi, S. A., \& Hershey, K. L. (1994). Temperament and social behavior in childhood. Merrill-Palmer Quarterly, 40, 21-39.

Rothbart, M. K., \& Bates, J. E. (1998). Temperament. In W. Damon (Series Ed.) \& N. Eisenberg (Vol. Ed.), Handbook of child psychology. Vol. 3. Social, emotional, personality development (pp. 105-176). New York: Wiley.
Rushton, J. P., Chrisjohn, R. D., \& Fekken, G. C. (1981). The altruistic personality and the self-report altruism scale. Personality and Individual Differences, 2, 1-11.

Rushton, J. P., Fulker, D. W., Neale, M. C., Nias, D. K. B., \& Eysenck, H. J. (1986). Altruism and aggression: The heritability of individual differences. Journal of Personality and Social Psychology, 50, 1192-1198.

Schwartz, S. H. (1968). Words, deeds, and the perception of consequences and responsibility in social situations. Journal of Personality and Social Psychology, 10, 232-242.

Staub, E. (1974). Helping a distressed person: Social, personality, and stimulus determinants. In L. Berkowitz (Ed.), Advances in experimental social psychology (Vol. 7, pp. 293-341). New York: Academic Press.

Underwood, B., \& Moore, B. (1982). Perspective-taking and altruism. Psychological Bulletin, 91, 143-173.

Weinberger, D. A. (1991). Social-emotional adjustment in older children and adults: I. Psychometric properties of the Weinberger Adjustment Inventory. Unpublished manuscript, Case Western Reserve University.

Weinberger, D. A. (1997). Distress and self-restraint as measures of adjustment across the life span: Confirmatory factor analyses in clinical and nonclinical samples. Psychological Assessment, 9, 132-135.

Zahn-Waxler, C., Robinson, J., \& Emde, R. N. (1992). The development of empathy in twins. Developmental Psychology, 28, $1038-1047$. 